\title{
18 Another Look at Preposition Stranding: English and Swedish Discourse Patterns
}

Francesco-Alessio Ursini

Stockholm University

\section{Introduction: Basic Aspects of Preposition Stranding}

Preposition Stranding (henceforth PS) is a syntactic construction that can be found across Germanic languages (Bolinger I977, I978). PS involves a non-canonical word order, in which a preposition and its object noun phrase (henceforth NP) are not adjacent, hence they appear to be "stranded". PS includes three sub-types of constructions: pseudo-passives, relative clauses and $w$ h-constructions (Koopman 2000). The existence of PS in Southern and Western Germanic languages, such as German and Dutch, is considered a controversial matter (van Riemsdijk I990, I998; Maling \& Zaenen I985; Truswell 2009). However, PS is certainly attested in English and most Scandinavian languages including Swedish, Norwegian, Danish, and Icelandic (Áfarli I992; Takami I992; van Riemsdijk I998; Law 2005; Klingvall 20I2). Interestingly, some of these works observe that PS seems to be an uncommon construction in Swedish (Takami I 992; Klingvall 2012). For this reason, in this paper we concentrate on English and Swedish, in order to address whether this phenomenon can receive a unified account across both languages, regardless of its language-related frequency. We start by discussing some preliminary examples in $(\mathrm{I})-(8)^{\mathrm{T}}$ :

(I) (This chair) $)_{i}$ was sat on $(\mathrm{NP})_{\mathrm{i}}$ (by Luigi)

(2) (The room) that/Ø we went into $(\mathrm{NP})_{i}$ is occupied

(pseudo-passive)

(relative clause)

${ }^{\mathrm{r}}$ The examples in (I)-(8) have been adapted from (corpora-based) examples found in previous literature, in particular Takami (I992) (Swedish), Truswell (2009) (English). The discourse-bound examples in (9)-(I4) have been also tested with the help of native speakers of either language, which we thank for their patience.

How to cite this book chapter:

Ursini, F.-A. 20I 5 . Another Look at Preposition Stranding: English and Swedish Discourse Patterns. In: Shaw, P., Erman, B., Melchers, G. and Sundkvist, P. (eds) From Clerks to Corpora: essays on the English language yesterday and today. Pp. 323-347. Stockholm: Stockholm University Press. DOI: http://dx.doi.org/Io.I6993/bab.r License: CC-BY. 
(3) (Which apples) $)_{\mathrm{i}}$ are you talking about $(\mathrm{NP})_{\mathrm{i}}$ ?

(wh-construction)

(4) (De här sängarna) ${ }_{i}$ har sovits $i(N P)_{i}$

(The here beds) ${ }_{\mathrm{i}}$ have been slept in $(\mathrm{NP})_{\mathrm{i}}$

(pseudo-passive)

'These beds have been slept in'

(5) *(De här sängarna $)_{i}$ har sovits $i(\mathrm{NP})_{i}$ av Jon (The here beds) have been slept in (NP) ${ }_{i}$ by John 'These beds have been slept in by John'

(6) Dörr-en är målad av Jon

Door-ART is painted by John

(passive)

'The door has been painted by John'

(7) (Det rum) som/(Ø) vi har betalat 300 kronor för (NP) ${ }_{i}$ är ledigt

(The room $)_{i}$ that $/(\varnothing)$ we have paid 300 crowns for $(\mathrm{NP})_{\mathrm{i}}$ is vacant

'The room that we have paid 300 crowns for is vacant'

(8) (Vilk-a äpple-n) ${ }_{i}$ pratar du om (NP) ?

(Which-PL apple-PL) $)_{i}$ talk you about $(\mathrm{NP})_{\mathrm{i}}$ ?

(wh-construction) 'which apples are you talking about?'

The "basic" position of the stranded NP is indicated via brackets; original and stranded NPs share the same index in order to highlight their structural relation. The English examples in (I)-(3) show that the NPs this chair, the room and which apple appear stranded from their governing prepositions, respectively on, into and about. Note: that in (2) can be omitted, a fact we represent via the symbol " $\varnothing$ " to represent phonologically null/silent heads. The examples in (4)-(8) offer an illustration of PS in Swedish: pseudo-passives (i.e. (4)-(5)), standard passive constructions (i.e. (6)), relative clauses (7) and $w$ h-constructions (i.e. (8)). These examples suggest that PS in Swedish follows similar but not identical patterns of distribution to English, principally centred on two properties.

First, Swedish pseudo-passive sentences cannot include the "passive" preposition $a v$ 'by', as examples (4)-(5) show ${ }^{2}$. Swedish passive sentences,

2 There is an ongoing debate concerning which prepositions can occur in pseudo-passives (Abels 2003: ch.I-2). We gloss over this debate here, since it is orthogonal to our discussion. 
on the other hand, can normally include av, like their English counterparts, and introduce the deep subject NP (John, in (6)). Second, Swedish pseudo-passives include the auxiliary verb $h a$ 'to have', rather than vara 'to be', as their passive counterparts (Holmes \& Hinchcliffe 2008: ch.3). Thus, Swedish pseudo-passive and passive sentences are not as closely related as their English counterparts. Examples (7)-(8), instead, show how relative clause and $w h$-constructions sub-types of PS are realized in Swedish. The relative pronoun som 'that' may be freely omitted, as in the case of English. In wh-constructions, the wh-pronoun vilka 'which' combines with the NP äpplen and agrees in number, as the glosses suggest.

As the examples seem to suggest, the PS patterns in both languages seem relatively clear. However, theoretical accounts of PS offer fairly different analyses of this phenomenon. Simplifying matters somewhat, classic and minimalist (transformational) proposals offer a movement-based analysis (Hornstein \& Weinberg I98I; van Riemsdijk I990, I998; Maling \& Zaenen I985; Koopman 2000; Truswell 2009). According to these analyses, PS is an operation that targets NPs and moves them into sentence-initial position. In our examples, the bracketed and indexed NPs mark the starting position of the NPs that are moved in sentence-initial position. Within non-transformational theories, one analysis about PS exists within "Head-Driven Phrase Structure Grammar" (henceforth HPSG). The analysis found in Tseng (2000, 2004 , 2005) suggests that PS involves two "copies" of the same NP, the two indexed NPs in our example. The sentence-initial copy, instead of the original copy, is the only phonologically realized copy in a sentence. Qua copies, both NPs must be identical in form; if they are not, PS cannot be licensed. Although other analyses of PS could certainly be formulated, this analysis represents the most prominent proposal, within this non-transformational framework.

Given these assumptions and the data in (I)-(8), it seems that both types of approaches can offer equally plausible, although theoretically different accounts of PS. Two questions that arise at this point, given this equilibrium among proposals, can be formulated as follows. A first more empirical question is whether we can discuss a broader set of data, in order to better understand the predictive power of these approaches. A second more theoretical question is whether we can offer a third, alternative analysis of this broader set of data that can perhaps improve upon previous analyses.

The goal of this paper is to offer an answer to this question by offering a "third way" analysis of PS. This analysis is couched in Type-Logical 
Syntax, a formal, non-transformational approach to morpho-syntactic structures (Morryll 20II). Via this approach, we first offer a more flexible approach to the lexical properties of our NPs. Then, we sketch an analysis that shows how these properties are related to syntactic structures, and that a unified account of PS in English and Swedish is possible and could perhaps be seen as theory-neutral, to some extent. To offer this solution, we follow this plan. In section 2, we present the inter-sentential data; in section 3 , we introduce our framework; in section 4, we offer our analysis, and compare it with previous analyses; in section 5 , we offer some conclusions to the paper.

\section{The Data: PS Licensing in Inter-Sentential Contexts}

Standard theoretical analyses of PS tend to focus on intra-sentential data, as (I)-(8) show. However, descriptive works usually observe that PS is often licensed in certain inter-sentential contexts, as well. A common pattern is that when the stranded NP denotes a specific, definite referent in discourse, then PS can be licensed, although this is not a necessary condition. This often represents the preferred word order for a sentence (Huddlestone \& Pullum 2002: I37-I4O; Holmes \& Hinchcliffe 2008: I40; Ward \& Birner 2012: I938-I942). This can be the case, as PS can license the formation of anaphoric relations between a stranded NP and a possible antecedent, insofar as these NPs select the same referent in discourse. These anaphoric relations act as ties that establish the cohesion of a text, and can be established both as relations between (argument) NPs, but also via other devices (e.g. temporal relations). Since these factors play a key role in our discussion, we discuss cohesion and anaphoric relations in a compact but accurate manner, in the remainder of this section.

We start with cohesion, and define it as a syntactic property of sentences in a text to express information about the same topics and referents in discourse (Kehler 20II: I964). One way to achieve cohesion is to have NPs referring to the same entities in sentence-initial position (the same chair, in ex. (9) below), in any sentence after the initial sentence. This is because the sentence-initial position is often reserved for topical noun phrases, which usually convey "old" information (Zeevat 20II: 956; Ward \& Birner 20I2: I945-I948). Another way to achieve coherence is also by establishing precise temporal and causal relations among the events described by each sentence (Zeevat 20II: 957-958; Kehler 20II: I965). A possibility that arises, then, is that PS may or 
may not uniquely determine whether a mini-discourse is cohesive: when the stranded NP conveys information about an "old" referent. I show these patterns in English via (9)-(I I), in which I index the anaphorically related NPs via sub-scripts:

(9) I bought (this chair) $)_{i} /(\text { a chair })_{j}$ on the left. (The chair $)_{\mathrm{i} / \text { /fj }}$ has been sat on

(Io) (This room) is free. (The room $)_{i} /(\text { a room })_{\# j}$ that we went into is not

(I I) A: (Which apples) i are you talking about?

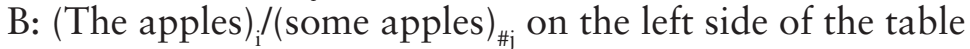

I concentrate on cases in which PS seems to be the key construction that allows the formation of anaphoric relations. In (9), sequence of tenses "simple past; present perfect" does not allow the formation of clear temporal relations. Thus, the event of buying the chair on the left and somebody sitting on it may be not causally "connected", but just occur in the past, with respect to the moment of utterance. The same reasoning can be applied to (IO)-(I I), although the sequence of tenses is different. In these cases, I would like to suggest that PS is the key syntactic construction that allows cohesion to be established. Since precise causal and perhaps temporal relations between the events that the sentences describe seem to be lacking, PS seems to be the key factor that licenses a cohesive mini-text ${ }^{3}$. The principle behind this relation can be described as follows.

If a first sentence introduces a definite and specific NP, such as the chair, then PS is licensed in a second sentence, as (9)-(I I) suggest. If an indefinite, non-specific NP such as a chair is introduced, instead, the whole mini-text becomes incoherent, as the "\#” and the lack of matching indexes display ( $i$ on the chair, $j$ on a chair) in each example. This is because the sentence-initial NP matches in features (the combination of definiteness and specificity, in (9)-(I I )) with the previous NP, otherwise they cannot possibly refer to the same entity in discourse: that is, be anaphorically related. Thus, it seems that when no other

3 An important aspect is that other parts of speech can license the formation of temporal, anaphoric relations. An anonymous reviewer observes that the presence of sentence-final adverbs could render a mini-text involving an indefinite-definite NP sequence cohesive (I bought a chair yesterday. The chair...). In other words, PS may also involve non-matching NPs, but when other anaphoric relations allow cohesion to emerge. In these cases, the relation(s) between NPs are semantic in nature, hence beyond the scope our discussion. See however von Heusinger (2007); Zeevat (20I I) and references therein, for discussion. 
anaphoric relations can be established, an NP should be stranded from its preposition for a text to achieve cohesion. Furthermore, this stranding procedure seems to involve "feature-matching" as a condition that licenses anaphoric relations. Note that what is at stake in these cases is cohesion, not ungrammaticality. Each sentence in a mini-discourse can be perfectly grammatical, and yet the resulting text can fail to be cohesive, if no anaphoric relations are established.

This fact seems to hold for each of the three PS-type constructions, as examples (9)-(II) suggest. These examples also show that the stranded NPs are not formally identical to their anaphorically related NP. Consider (Io), for instance: the two NPs this room and the room share the same values of specificity and definiteness, as a deictic phrase and a definite noun phrase, respectively (Heusinger 2007, 20I I; Diessel 2OI2). Furthermore, the question in (II) contains a form of wh-construction PS, and can be answered only via an answer that also contains a definite and specific NP, in this case the apple, otherwise the answer is incohesive (cf. Krifka 200I, 2004). Thus, one type of anaphoric relation is established when two NPs carry matching morphological features, even if the NPs do not belong to exactly the same (syntactic) sub-type. Examples (I 2)-(I4) show that a similar picture holds for Swedish, but with certain differences:

( (12) Jag köpte (stolen) I(någon stol) ${ }_{i}$ till vänster.

(Den här stolen) ${ }_{i / \# i}$ var sutten $p a ̊$

I bought (chair-ART)i/(some chair)j to left-ART

(The here chair) $)_{\mathrm{i} / \# \mathrm{j}}$ was sat on

'I bought the chair/a chair to the left. This chair was sat on'

(I3) (Detta rum) ${ }_{i} \ddot{a r}$ ledigt. (Det rum) $/(\text { (något rum })_{\# j}$ som vi gick in $i$

är det inte

(This room)i is vacant. (The room)i/(some room) \#j $_{\mathrm{j}}$ that we went into is it not

'This room is vacant. The/a room that we went in is not'

(I4) A: (Vilk-a äpple-n) ${ }_{i}$ pratar du om?

(Which-PL apple-PL) talk you about?

'Which apples are you talking about?'

B: (Äpple-na) /(några äpple-n $)_{\text {\#j }}$ på vänster sida av bord-et

(Apple-PL.ART) $)_{\mathrm{i}} /(\text { some apple-PL.ART })_{\# \mathrm{j}}$ on left-ART side of table-ART

'The apples/some apples on the left side of the table' 
Example (I 2) shows that when the non-specific någon stol 'a chair' (lit. 'some chair') occurs in the first sentence, the NP den här stol 'this chair' does not find a suitable antecedent. This is the case, as nagon stol is an antecedent NP that does not match the features that Den här stolen carries. The net effect is that the speaker appears to identify via the second sentence one chair that, however, was not mentioned in the first sentence. Thus, the mini-discourse appears incohesive, since no other anaphoric relations (e.g. temporal ones) are established. The same patterns emerge in (I3)-(I4), modulo the slightly different types of NPs and PS constructions involved ${ }^{4}$. Hence, both specificity and definiteness seem to play a role in the distribution of PS in discourse, as these features allow the establishment of cohesion (or lack thereof) in a text, when no other anaphoric relations can be established. Hence, an analysis of this phenomenon must include a treatment of the role of these features, and their relation to word order and cohesion.

One interesting dilemma that these data present consists in assessing the exact nature of this problem. From a theoretical perspective, specificity and definiteness are features that play a role at a morphological and semantic level of representation. The morphological values permit an anaphoric relation between two NPs to be established, and the related mini-text may become cohesive as a result. Both the chair and this chair are specific, definite NPs that can refer to a given chair. Hence, they can refer to the same chair in discourse, and license a discourse that is also semantically coherent (Kehler 20II; Zeevat 20II). As our data suggest, our problem regarding the nature of PS seems to involve a complex interplay between morphological, syntactic and semantic levels of representation.

As a consequence of this pin-pointing the nature of our PS dilemma, our empirical question can now receive a precise formulation. The extension of either current HPSG or minimalist analyses of PS to these data does not appear as a simple matter. One problem that both approaches share pertains to the feature values of anaphorically related NPs. The approach outlined in e.g. Tseng (2000: ch.4) includes an inter-sentential treatment of anaphoric phenomena that transformational approaches lack (Klingvall 20I2), but the morpho-semantic

${ }_{4}$ We note here that this pattern emerges when indefinite and non-specific NPs such as någon stol are involved. Swedish differs from English in having a second indefinite article: en lit. 'one', ambiguous with respect to specificity. However, in PS constructions en can only have specific value (e.g. en stol 'one (specific) chair', in (I2)). Our analysis can be extended to en as well, but the use of nagon in our example better highlights the parallels between Swedish and English PS constructions. 
problem of anaphora resolution would remain intact. This is the case, as this approach crucially relies on copied NPs and their phonologically realized counterparts to be formally identical. Our data in (9)(I4) suggest that this assumption is not tenable, at an inter-sentential level. Two NPs can be anaphorically related, license PS and a cohesive text, as long as they both carry the definiteness and specificity features. Therefore, a more flexible approach seems to be called for. Since both current analyses of PS seem to be problematic, we propose a third analysis in the next section.

\section{The Proposal: An extended TL calculus}

In this section our formal analysis is based on a framework known as Type-Logical calculi (henceforth TL, Jäger 200I, 2005; Moortgat 20I0, 20II; Morryll 20II). Our variant of TL implements some assumptions from certain variants of minimalist syntax, notably Distributed Morphology (Embick \& Noyer 200I; Harbour 2007; Harley 20I2). However, the proposal I wish to make takes an inherently non-transformational perspective, in part closer to HPSG and other similar frameworks. I will spell out these assumptions, as we proceed in our presentation of the framework. We choose our variant of TL for two reasons. First, TL is a formally explicit framework that can treat morphological and syntactic data alike, without any supplementary assumptions specific to each domain. Second, it offers tools that allow one to easily analyse inter-sentential data, at least in our formulation. Here we offer a compact discussion; a more thorough presentation of this framework is found in previous work of the author (Ursini 20II, 20I3 a, b, c, 20I 5 a, b; Ursini \& Akagi 20I3 a, b). I present some key assumptions of our TL analysis, then we move to our innovations.

First, parts of speech are mapped onto or assigned types, which can be considered as either being "complete" or "incomplete" bits of morpho-syntactic information. Complete types represent constituents that can stand as distinct, independent constituents (e.g. $n p$ for NPs such as the girl). Incomplete types represent constituents that must combine with other constituents to form a complete unit. An intransitive verb such as runs can be assigned type $n p \backslash s$, since it can combine with an $n p$, the girl. The result is the sentence the girl runs, which is assigned the type $s$ of sentences. Thus, types can also be used to represent the syntactic valence of lexical items, and possible restrictions on which types of arguments/phrases heads can take. 
Second, we implement two connectives, "/" and ".", that are known as the right division (or just division) and the product connectives (Moortgat 20I0: $\$ 2$; Morrill 20I I: ch. I). Both connectives are binary and associative, but product is also non-commutative. Products of types (e.g. $a \cdot b)$ are taken in this order. Third, we follow some TL calculi that take a psycholinguistic model of sentence production, and propose that sentences are derived in a top-down ("left-to-right", in linear terms) manner (Morryll 20II). This assumption is also found in psycholinguistics models such as Levelt (1989); Phillips (2006); Jarema \& Libben (2007). More importantly, this assumption will turn out to be germane to our goals, since it allows us to treat anaphoric phenomena in a straightforward manner, as shown in section 4 . The three assumptions represent innovations that I introduce with respect to standard TL calculi.

First, I leave aside other standard TL connectives, such as left division "।” and Jäger's (200I, 2005) connective "|” for anaphoric relations. In particular, I will suggest a way to treat anaphoric relations that exclusively rely on the interplay of division and product known as the merge schema, in part adumbrated in Jäger (200I: 78-8I). I aim to show that, once we offer a formal analysis of the distributional properties of our lexical items, our basic combinatorial system will suffice to account for our data. Specifically, I aim to show that our PS data require a simple but precise analysis of the distribution of prepositions and nouns based on their morphological features.

Second, I take a more sophisticated view concerning types other than the one found in standard TL calculi, as we follow recent analyses on the nature of morpho-syntactic categories. Thus, I assume that lexical and functional categories are not primitive categories, but clusters of morphological features (Hale \& Kayser 2002; Harbour 2007; Adger 20I0; Acquaviva \& Panagiotidis 20I2). For instance, nouns include features such as gender and number while prepositions lack these features, but they may include a "spatial" feature or similar other non-nominal features. Hence, in our system morphemes correspond to products of features, which can then differ with respect to value they can carry (e.g. "male" or "female" for the gender feature). Here I follow proposals that assume the "separation hypothesis": vocabulary insertion occurs after morphological derivations (Levelt I989; Embick \& Noyer 200I). Thus, abstract morphological objects may lack an overt phonological exponent, or are realized by different exponents across languages (here, that vs. som: Embick \& Noyer 200I). We return to this point in section 4 . 
Third, I assume the distributional properties of categories can be represented explicitly, via our type system. If transitive verbs (loves) and prepositions (e.g. to) act as heads with 2-valence, then their type should reflect this shared property. Hence, different categories and constituents (verbs, prepositions, phrases, sentences, and discourses) can be reduced to a handful of types. Depending on the valence of a constituent, one can determine the type assigned to this constituent. I capture this assumption by using only one basic type $p$, which is mnemonic for both "phrase" and "product of features". The rules for deriving other types are defined in (I 5 ):

(I 5) I. $\mathrm{p}$ is a morphological type (Lexical type)

2. If $x$ is a type and $y$ is a type, then $x / y$ is a type (Type I.: Division)

3. If $x$ is a type and $y$ is a type, then $x \cdot y$ is a type (Type I.: Product) 4. If $x / y$ is a type and $y$ is a type, then $(x / y) \cdot y \vdash x, y \cdot(x / y) \vdash x$ (MI: For. A.)

5. If $x / y$ is a type and $y / z$ is a type, then $(x / y) \cdot(y / z) \vdash x / z$ (MI: Cut rule)

6. Nothing else is a type (Closure rule)

In words, rule I introduces our basic type $p$. Rule 2 says that two basic types combined via division $(x, y)$ form a complex type, e.g. a head which can take one argument (here, $x / y$ : a definite article taking an NP as an argument, as in the car). Rule 3 says that two basic types combined via product form a complex type that bundles information (i.e. $x \cdot y$ ). Rule 3 can also be used to introduce information (i.e. from $x$ to $x \cdot y$ ), in a manner that we will discuss thoroughly in section 4 . In this case, we take our basic type to represent single features, a move that we also fully motivate in section 4 .

Rules 4 and 5 introduce two instances of merge schemas, rules that govern how (right) division and product types interact. Rule 4 is known as forward application. It says that the product of a complex (division) type and a simple type yields a certain output type, provided that the input type of the complex type (here, $y$ ) matches that of the simple type. Thus, rule 4 governs how a head can combine with an argument to form a more complex constituent such as a phrase, for instance. It also determines what the output of this phrase is (here, $x$ ), provided that the two input types "match". As rule 4 plays a crucial role in our analysis, we return to the specific details of its application when we discuss the data. 
Rule 5 is a merge schema known as the cut rule, and says that two complex types sharing their "internal" type can be combined into a new type. This rule plays a key role for the analysis of our discourse data; we delay a more precise explanation to section 4 . Rule 6 says that no other rules are necessary. In our system, the symbol “ト” represents the merge schemas as ternary relations between the types of two input constituents and the type of their output, the constituent they form when merged together. If the NP the girl and the verb runs are assigned matching types, their merge will form the VP the girl runs. As a consequence, in our system rules 4 and 5 offer two formally precise schemas to "prove" that larger constituents can be formed, via our basic set of rules and types.

Overall, our minimal set of derivational rules allow us to generate complex type sets, intended as types that we can assign to our constituents. For our purposes, the set TYPE $=\{p \cdot p, p \cdot p / p \cdot p, p \cdot p / p \cdot p / p \cdot p\}$ will suffice to account for all the data at hand. This set respectively includes arguments taken as bundles of features, I- and 2-valence heads. The precise nature of these types will become clear when we discuss how and why these types are assigned to our constituents, in the next section. However, before we introduce our analysis, we must discuss one last aspect of our formal apparatus. In order to capture the incremental nature of our derivations, we define a simple pre-order as the pair of an interval set $I$, and an addition operation “+”, i.e. $\langle I,+\rangle$. This pre-order represents an index set, which in turn allows the representation of all the steps in a derivation as sequential elements (e.g. $t, t+I, t+2$, etc.). We also implement two labels, Lexical Selection (LS) and Merge Introduction $^{5}$ (MI) in order to explicitly mark the introduction of a new element in a derivation, and the merge of two elements, respectively. With this formal apparatus at our disposal, we move to our data.

\section{The Analysis: The Distribution of PS}

The goal of this section is to offer our TL analysis of the data. We start by motivating our type assignment for our constituents, before moving to the derivations that illustrate how we can account for our data.

5 In TL calculi, merge is an elimination, rather than introduction rule for division: It removes slashes in a structure. The label "introduction" stresses that morphemes are combined into more complex structures. 
We start by motivating which categories are assigned the (product) type $p \cdot p$, which represents phrases that carry bundled morphological features. We assign this type to NPs qua phrasal arguments of a head. As our examples show, NPs carry (at least) the features $p_{+f}$ or $p_{-f}$, for specificity, definiteness and similar other features. This simple fact seems to motivate the use of a product type for NPs. We then assume that wh-phrases which apples and vilka äpplen can be assigned the same type. We thus follow standard treatments of this category, although we choose a more coarse-grained perspective than standard analyses of wh-phrases (Alexiadou et al. 2000; Bianchi 2002a, b; Vermaat 2005). We represent this complex type as $p_{ \pm s p e c}$, for simplicity, and leave the values for definiteness, (plural) number, pronominal and relative features implicit, in our analysis. Nothing crucial hinges on this notational simplification.

As our initial type assignment shows, we also assume that features can have different values, which can in turn determine whether an instance of merge is successful or not. Analyses of feature systems abound in the literature, in TL calculi and other frameworks (Johnson \& Bayer I995; Bernardi \& Szabolcsi 2008; Tseng 2005; Adger 2010; Stabler 2013). As we only discuss cases in which the binary value(s) of features may determine the well-formedness or cohesion of a syntactic (or discourse) derivation, our analysis has an inherently theory-neutral perspective. However, the core aspects of our analysis are based on Johnson \& Bayer (I995) and their proposal on feature percolation, as it will soon become clear.

We move to spatial prepositions, as we wish to offer an argument for assigning them the type $p \cdot p$ as well. Several minimalist analyses treat these prepositions as sequences of functional heads, which may or may not be phonologically realized. Thus, a non-stranded preposition such as in would be assigned the type $p \cdot p / p \cdot p / p \cdot p$ of heads, with its complement phrase being an NP. A stranded preposition would be assigned the same type, but it would also combine with a non-pronounced (silent) copy of the stranded NP (Koopman 2000; Truswell 2009; Svenonius 2006, 2010). Here we follow a different minimalist analysis of SPs, sometimes known as the "P-within-P" hypothesis (Hale \& Kayser 2002; cf. also Emonds I985; van Riemsdjik I990, I998). This analysis suggests that spatial prepositions involve a complex structure, in which a silent prepositional head takes another preposition as its specifier phrase ${ }^{6}$. Hence, a prepositional phrase such as in the garden

${ }^{6}$ TL calculi usually do not employ "silent" categories, although this assumption is not uniform (cf. Jäger 2005: ch. 2 vs Moortgat 20I I $\$ 2$ ). This matter is not crucial, for our discussion. 
would involve the phrase in (i.e. the "internal" preposition), a silent head " $(\mathrm{P})$ ", and the complement phrase the garden.

Via this assumption, our prepositions occurring in PS contexts are assigned the type $p \cdot p$, which is the same type they would receive in a non-stranded position. A minimal proviso is that when these prepositions occur in stranded positions, they act as complements of a verb, rather than specifiers of another preposition. Thus, prepositions such as in in the room we went in have a particle-like distribution, as complements of the verb (here, went: Åfarli I992; Abels 2003). Importantly, although spatial prepositions and NPs are assigned type $p \cdot p$, they differ in the values of the features they carry as phrases. For instance, prepositions seem not to carry the feature value ${ }_{p \pm s p e c}$ of NPs, a minimal morphological difference that suffices to distinguish these two categories. Both categories, though, can act as arguments of relational heads, something we represent via the general use of product types for phrases.

We move to our analysis of heads: verbs, prepositions introducing pseudo-passive constructions and complementizers. We assign the type $p \cdot p / p \cdot p / p \cdot p$ of 2 -valence heads to these three categories, although with some minimal differences. First, verbs carry a "voice" feature, thus either a passive or active value on their output type. They can only merge with a preposition that matches these features, such as passive prepositions. For the sake of simplicity, we treat compound verbs as forming a single lexical unit: both har sovits 'have been slept' and has been sat receive this type, $q u a$ verbs. We thus assign type $p \cdot p_{+s p e c} / p \cdot p_{ \pm-}$ pass $/ p \cdot p$ to each verb ${ }^{7}$, depending on whether it has active or passive voice. Note that since temporal features do not play a crucial role in the analysis of our examples, we omit them. However, a more thorough analysis of PS patterns could be offered, by adding a discussion of these features and their role in forming cohesive texts. We leave such an extension aside, for the time being.

Second, we also assign the type $p \cdot p_{\text {pass }} / p \cdot p / p \cdot p$ to passive prepositions (by, $a v)$ as heads, for a simple reason. Standard analyses of passive sentences suggest that these prepositions take the deep subject NP (Luigi in (I)) and the passive verb phrase (e.g. this chair has been sat on in (I)) as arguments (Abels 2003; Gehrke \& Grillo 2009; Ishizuka 2010). Thus, their specifier input type must carry a passive feature value. Third, we also assign this relational type to complementizers, as heads

7 For simplicity, rather than for necessity, we also assume that our heads always take a specific (specifier) input type $p \cdot p_{+s p e c}$, since all our examples involve specific NPs. 
introducing relative clauses (that, som), in line with standard assumptions (Alexiadou et al. 2000; Bianchi 2002a; Vermaat 2005). We thus assign the type $p \cdot p_{+s p e c} / p \cdot p_{\text {rel }} / p \cdot p$ to this category. Before we show how these types can be combined together to form our sentences, we summarize our type assignment in (I6):

(г6) a. $p \cdot p=\{$ this chair, de här sängarna, up, $i$, which apples, vilka äpplen\}

b. $p \cdot p / p \cdot p / p \cdot p=\{$ was sat, $b y, a v$, that, som $\}$

From this type assignment and the rules in (15), we can offer an account of how our examples are derived, starting from pseudo-passives. We repeat (I) as (I7a) to illustrate our account. We use simplified nota-

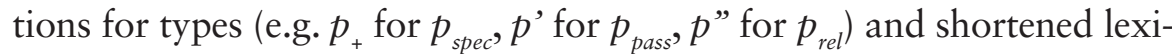
cal entries in our derivations (e.g. this for this chair) for reasons of space:

(I7) a. This chair was sat on by Luigi

b.t. [ this chair $\left.{ }_{p \cdot p+}\right]$

$t+I$. [ was sat $\left.{ }_{p \cdot p+p \cdot p \cdot p^{\prime} \mid p \cdot p}\right]$

$t+2$. [ this chair $\left.{ }_{p \cdot p+}\right] \cdot\left[\right.$ was sat $\left.{ }_{p \cdot p+\mid p \cdot p p^{\prime} / p \cdot p}\right] \vdash$

$t+3 .\left[\right.$ on $\left._{p \cdot p \cdot p}\right]$ [ this chair $\left.{ }_{p \cdot p+}\right]$ was sat $\left.{ }_{p \cdot p+\mid p \cdot p^{\prime} / p \cdot p}\right]$

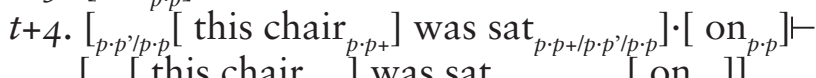

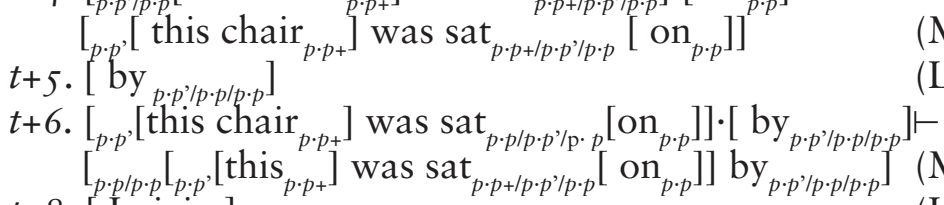

$t+8$. [ [ Luigi $\left.{ }_{p \cdot p}\right]$

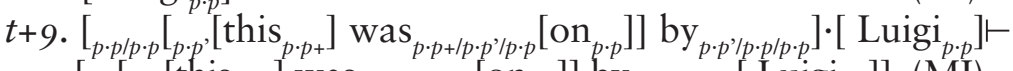

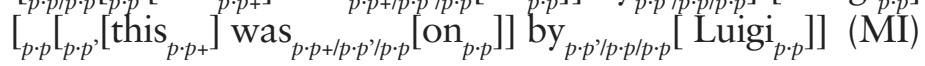

Our derivation reads as follows. The NP denoting the object, this chair, merges with the passive verb was sat. The result of this operation merges with the spatial preposition on, thus deriving the VP this chair was sat on (steps $t$ to $t+4$ ). The preposition by carries passive features, and merges with the passive VP this chair was sat on. This is the case, as the passive feature values of the two merged constituents match (step $t+6)$. The deep subject NP Luigi is then merged, and (I7a) is derived accordingly (steps $t+7$ to $t+9)$. An important result of this derivation, then, is that the word order in a sentence involving PS can be derived without assuming silent or copied NPs in the sentence-final position. Thus, we can explain how English pseudo-passives are derived as complete sentences without resorting to assumptions involving copied/ 
moved constituents. Since we have also shown how a grammatical pseudo-passive sentence is derived, we can now show how an ungrammatical sentence is instead blocked. We do so by offering a "compressed" derivation for our Swedish example (5), repeated as ( I 8a):

( I 8) a. "De här sängarna har sovits $i$ av Jon

b. $t+6 .\left[_{p \cdot p}\left[\right.\right.$ De här sängarna $\left.{ }_{p \cdot p+}\right]$ har sovits $\left.{ }_{p \cdot p / p \cdot p / p \cdot p}\left[\mathrm{i}_{p \cdot p}\right]\right] \cdot\left[\mathrm{av}_{p \cdot p^{\prime} / p \cdot p / p \cdot p}\right]$ $\vdash *$

(Feature mismatch, derivation crashes)

We focus on the derivational step at which the derivation blocks or "crashes", $t+6$. The merge of a clausal phrase that lacks a passive feature (de här sängarna har sovits $i$ 'these beds have been slept in') and passive preposition results in a mismatch of features. Recall now that Swedish pseudo-passives differ from "true" passives by having ha 'to have' as the main auxiliary verb, hence being closer to active forms. This fact suggests that har sovits carries the opposite voice feature values of av. As we have established via rule 4, if two merged units do not match in type/feature value, then a derivation is blocked. Thus, ( $18 \mathrm{~b}$ ) suggests that our analysis predicts the ungrammaticality of (I $8 \mathrm{a})$ as a feature mismatch case. This basic aspect of merge, together with the type assignment for our English and Swedish lexical items, seems to suffice to explain this datum. Via this result, other data can now also be accounted for, a fact that we show by focusing on relative clause PS patterns in both languages. Recall that the difference between English and Swedish pertains to the exponent that realizes the complementizer head: that and som. If the exponents differ, but the lexical items that are merged are the same, then the same type of derivation can generate the structures of both English and Swedish relative PS sentences. We show this derivational symmetry in (19)-(20):

(I9) a. The room that we went into is occupied

$$
\begin{aligned}
& \text { b.t. [ the room } \left.\text { r.p+ }_{+}\right] \\
& \left.t+I \text {. [ that } t_{p \cdot p+\mid p \cdot \cdot / p \cdot p}\right] \\
& \left.t+2 \text {. [ the } \operatorname{room}_{p \cdot p+}\right] \cdot\left[\text { that }_{p \cdot p+/ p \cdot p^{\prime \prime / p \cdot p}}\right] \vdash \\
& \left.t+3 \text {. [ [ we went into }{ }_{p \cdot p}\right] \text { [ } \\
& t+4 \cdot\left[_{p \cdot p^{\prime \prime} / p \cdot p}\left[\text { the } \operatorname{room}_{p \cdot p_{+}}\right] \text {that } t_{p \cdot p+\mid p \cdot p / p \cdot p}\right] \cdot\left[\text { we went into }{ }_{p \cdot p}\right] \vdash \\
& {\left[\begin{array}{l}
{[p \cdot p} \\
.
\end{array}\right.}
\end{aligned}
$$

(20) a. Det rum som vi har betalat 300 kronor för är ledigt

b. t. [ det $\left.\operatorname{rum}_{p \cdot p+}\right]$ 


$$
\begin{aligned}
& t+I .\left[\operatorname{som}_{p \cdot p+|p \cdot p /| \cdot \cdot p}\right] \\
& \left.t+2 \text {. [ } \operatorname{det} \operatorname{rum}_{p \cdot p+}^{p \cdot p+p \cdot p_{+}}\right] \cdot\left[\operatorname{som}_{p \cdot p+\mid p \cdot p^{\prime \prime} / p \cdot p}\right] \vdash \\
& \left.t+3 .\left[\begin{array}{l}
p \cdot p / p \cdot p \\
\text { vi har betalat för }
\end{array} \text { det }_{p \cdot p}\right] \text {. } \text { rum }_{p \cdot p+p \cdot p / p \cdot p}\right]
\end{aligned}
$$

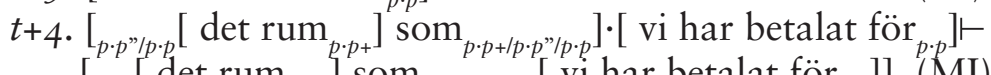

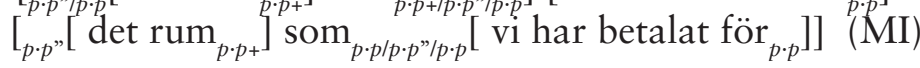

These derivations suggest that our subject relative clauses, such as the room that we went in, can include the stranded NP, in this case the room. Our type assignment and our derivational rules show that this subject relative clause is well-formed and can be merged with the rest of the sentence as a phrase (argument). Thus, our analysis of PS, when also applied to this type of PS constructions, seems to offer a parsimonious but overall accurate analysis of how the observed word order can be derived.

Before we move to $w h$-constructions, we discuss the optional/obligatory realizations of complementizers. Recall now that som and that may be omitted (cf. (2), (7)), a phenomenon that is "post-syntactic" in our account (Embick \& Noyer 200I). That is, it pertains to which vocabulary exponents are inserted in a derivation, not to the morpho-syntactic objects that are merged together. Thus, it can be based on language-specific ellipsis rules, which usually target specific feature values that elided categories can carry (Merchant 200I: ch. I-2, 2004). Since we distinguish between morpho-syntactic derivations and phonological operations, language-specific operations are a natural consequence of our approach, one example being relative clauses in PS contexts. Once we have this second piece of our PS puzzle in its correct place, we can offer an analysis of $w h$-pronoun PS constructions, which builds on the results obtained so far. We repeat (3) and (8) as (2 Ia) and (22a), to show this fact:

(2I) a. Which apples are you talking about?

b. $t$. [ which apples $\left._{p \cdot p+}\right]$

$t+I$. [ are you talking $\left.{ }_{p \cdot p+\mid p \cdot p / p \cdot p}\right]$

$t+2$. [ which apples $\left.{ }_{p \cdot p+}\right] \cdot\left[\right.$ [ are you talking $\left.{ }_{p \cdot p+p \cdot p / p \cdot p}\right] \vdash$ $\left[_{p \cdot p / p \cdot p}\left[\right.\right.$ which apples $\left.{ }_{p \cdot p+}\right]$ are you talking $\left.{ }_{p \cdot p+p+p \cdot p / p \cdot p}\right]$

(22) a. Vilka äpplen pratar du om?

b. $t$. [ Vilka äpplen $\left.p_{p \cdot p+}\right]$

$t+I$. [ pratar du $\left.\mathrm{du}_{p \cdot p+\phi \cdot p \cdot p / p \cdot p}\right]$

$t+2$. [ Vilka äpplen $\left.p_{p \cdot p+}\right] \cdot\left[\right.$ pratar $\left.\mathrm{du}_{p \cdot p+/ p \cdot p / p \cdot p}\right] \vdash$ $\left[\begin{array}{l}{[\cdot p / p \cdot p} \\ {[\text { Vilka äpplen }} \\ p \cdot p+\end{array}\right]$ pratar $\left.\mathrm{du}_{p \cdot p+p \cdot p / p \cdot p}\right]$ 
The partial derivations in $(2 \mathrm{Ib})$ and $(22 \mathrm{~b})$ read as follows. For the sake of simplicity, we treat both you and $d u$ as part of the verbal head, hence treating these pronouns as clitic-like elements (cf. Koopman 2000; Jäger 2005). These verbs merge with the relative NPs which apples and vilka äpplen 'which apples', which also carry a specificity feature. Since we do not explicitly represent other feature values, these derivations appear equivalent to those we offered in examples (I 8b)-(2ob). Since our type assignment for relative NPs and our derivational analyses prove that silent NPs must be merged into our sentences, we can extend our parsimonious analysis to this PS sub-type, too ${ }^{8}$.

We now have an account of each of the three sub-types of PS constructions in intra-sentential examples found in (I)-(8). Thanks to this result, we are in a position to also sketch an account for our inter-sentential examples in (9)-(I 4). For this purpose, I build on Jäger's (200I: 84-86) implementation of TL calculi to derive discourse structures. Differently from his proposal, however, we do not employ a special type for sentences as part of discourses (his type $D$ ). In our system, we assign type $p$ to sentences qua complete syntactic objects, as our derivations show. Thus, I sketch an approach in which the same logical analysis can be applied to different levels of structure, and merge can act as a schema that combines sentences into discourses.

We must now account for two important problems that arise at this level of analysis: inter-sentential anaphoric relations and, consequently, discourse cohesion. Since anaphoric relations can define the cohesion of discourses (Kehler 20II; Reuland 20II), their analysis can permit us to sketch a preliminary syntax of discourse that can also account for PS. For this purpose, I take the fairly standard assumption that a system of feature percolation is active (Adger 2010: I 88-195; Tseng 2005; Stabler 20I3). The theory-neutral assumption is that the features of constituents making up sentences can percolate at a sentence level, and constrain how anaphoric relations can be established. Insofar as at least one set of features can license the formation of anaphoric relations, then cohesion is obtained. Thus, PS can potentially permit the formation of a cohesive text, in cases when no other anaphoric relations can be established (i.e.

8 We must offer one caveat. We partly deviate from standard analyses of questions, including TL-based ones (Vermaat 2005), since we are concerned with offering an account of PS. While standard accounts of questions assign a type close to $p / p$, here we treat these types of sentences as if they were simple declarative sentences, of type $p$. This is a simplification, although a non-problematic one. 
our (9)-(I 4)). In order to capture these facts, however, we must capture how feature percolations systems work, in the first place.

For this purpose, I follow feature percolation systems found in TL calculi (Johnson \& Bayer I995; cf. also Bernardi \& Szabolcsi 2008). I assume that percolation involves the "duplication" of the feature types of an argument NP to the VP that contains this NP, as per rule 3 (type formation: product). Since we are discussing PS and its contribution to cohesion, we can restrict this assumption to the features that NPs contribute to a sentence. Hence, I assume that the features that allow the formation of an anaphoric relations are those that the stranded NP in the second sentence, and its non-stranded counterpart in the first sentence contribute. Thus, if $p$ represents the type of a VP such as ( I $7 \mathrm{a}), p \cdot p_{+ \text {spec }}$ can represent ${ }^{9}$ the type of this sentence, made ready to be merged with another sentence taking this type as an input ${ }^{\mathrm{to}}$. Once these features are percolated, an anaphoric relation can be established, and the two sentences that include these NPs form a cohesive discourse. In order to show how our analysis works, I repeat (9) as (23a) and offer its two simplified derivations in $(23 \mathrm{~b}-\mathrm{c})^{\mathrm{Ir}}$ :

(23) a. I bought the chair/a chair on the left. This chair was sat on by Luigi

$\left.\begin{array}{l}\text { b. } t . \quad\left[\ldots \text { the chair on } p_{p \cdot p_{+}}\right] \\ t+I \text {. [ This chair...p.p+ }\end{array}\right]$

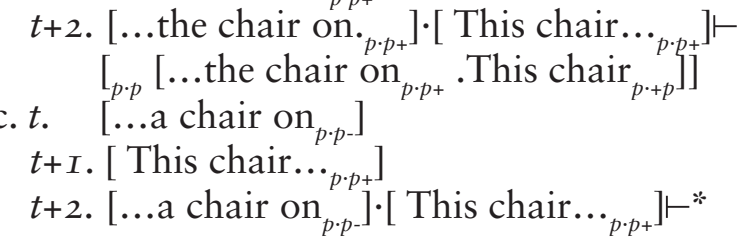

(MI: cut rule)

(Der. crashes)

In words, the two sentences I bought the chair on the left and this chair... are both assigned the type $p \cdot p_{+ \text {spec }}$. This is the type assigned to

9 This type minimally differs from the type assigned to NPs by the specific value assigned to $p$, since it may represent sentence types, rather than nominal types. Again, I do not explicitly represent this distinction, for mere reasons of space.

Io In this case, we assume rather than prove that our mechanism of feature percolation derives the results we discuss. See Bernardi \& Szabolcsi (2008: $\mathbb{I}$ I-2) for discussion. Note also that we implement product types, although the standard definition of the cut rule we offer is better suited for functional types.

${ }^{11}$ Our system could offer an incremental account of how these mini-discourses are derived, not unlike other related proposals in the literature (e.g. Asher \& Lascarides 2003). Here we only merge two fully formed sentences, in order to sketch how our apparatus works. 
sentences that receive the relevant features from one of their argument NPs via feature percolation. Via the cut rule, a merge schema and rule 5 in our set of rules, we can establish an anaphoric relation between NPs across sentences. In doing so, we also establish one form of cohesion between the sentences that contain them, as a reflection of the "matching" component of merge. In this way, we can offer a proof on how to derive our discourse example. Hence, our analysis can derive anaphoric relations that emerge in PS constructions, as instances of our general type-matching mechanism that is part of merge.

One important caveat is that our examples highlight the possible role of PS as one cohesion-building construction, but certainly as not the only construction to do so. Recall from section 2 that the verbs in our examples lack temporal features that permit to establish anaphoric relations between sentences. For instance, the event of buying a chair and that of someone sitting on this chair, described by the mini-text in (23), are not necessarily related. In this case, PS seems to reflect the fact that the only features that can percolate, and allow cohesion to be established, are those that the stranded NP carries. Consequently, the derivation in $(23 \mathrm{c})$ shows that when not even this anaphoric relation can be established, a mini-discourse becomes incohesive. The cut rule cannot merge two sentences that lack matching types, so a cohesive mini-discourse cannot be formed. Therefore, we can now capture the fact that PS can allow the formation of cohesive discourses, especially when no other constructions can do so.

Two other results that we obtain via our analysis are the following. First, we can now predict a preference for PS constructions in inter-sentential examples. This can be seen as a strategy that allows for an easy resolution of anaphoric relations, via cross-sentential feature-matching (Reuland 20I I; Ward \& Birner 20I2). Second, we can indirectly predict that, when other features can percolate at a sentential level, cohesion may be established even if a stranded NP does not match the features of its anaphoric counterpart. If the events described by each sentence are anaphorically related via e.g. temporal morphology on verbs and/ or adverbs, then we could expect that some chair could occur in (23a), and the mini-discourse be cohesive. If cohesion emerges insofar as the types of two sentences match on one feature (value), e.g. $p_{+t e n s e}$, then PS does not univocally determine the cohesion of a discourse. Once more, however, our examples suggest that it may play this role, given the more general mechanisms that govern cohesion. Thus, an extension of our analysis could ideally account for these data, as well. 
Given these two results, we have now shown how our non-transformational analysis can now derive all the examples in (I)-(I4) in a principled and parsimonious way. As we have reached our main goal, we can move to the conclusions.

\section{Conclusions}

In this paper we have offered an account of Preposition Stranding (PS) and its three sub-types (pseudo-passives, wh-constructions, relative clauses) in English and Swedish. We have suggested that the three assumptions on which our account rests upon can offer an empirically broader and theoretically parsimonious analysis of this phenomenon. Our first assumption is that, if we treat morphological features as "bits" of information, then we can successfully account for how (and when) stranded constituents are inserted (merged) in a sentence. Our second assumption is that, if we pursue a top-down ("left-to-right") derivational approach to sentences, then we do not need copying/movement analyses to account for word order in PS constructions. Our third assumption is that the feature-matching aspect of merge suffices to capture the anaphoric relations that arise between sentences when PS constructions are involved, and that can create discourse cohesion. This is obtained via a very simple system of feature percolation that simply copies "old" morphological information at the level of discourse (here, the specificity and definiteness of NPs).

Thus, our account seems to be successful in explaining our data, and seems to sketch an alternative analysis to both minimalist proposals (Truswell 2009) and HPSG-based proposals (e.g. Tseng 2000). However, nothing prevents that feature-based proposals can be offered within these frameworks, that can cover our data and perhaps broader sets, in a similarly accurate manner. I would like to suggest that the current analysis can indeed be seen as complementing and enriching previous analyses, as well as our understanding of PS as a syntactic construction and its relation to discourse structure and cohesion (cf. Ward \& Birner 2012).

It is goes without saying that we have not exhausted the discussion on PS. For one thing, we have focused on a specific sub-set of data, and left aside the possibility that PS can interact with other syntactic constructions, and partake in a fairly complex interaction between feature percolation and cohesion phenomena. This has been a necessary choice, given our limits of space and the complexity of PS as a general 
phenomenon. We also have left aside a discussion of other Scandinavian languages, such as Norwegian or Icelandic, in which PS seems to be a more common, but also a more complex phenomenon. Also, we conjecture that this approach can also potentially offer a morpho-syntactic counterpart of the semantic treatments of anaphoric relations (Elbourne 2005; Kamp, van Genabith \& Reyle 20II). Furthermore, our work sketches the possibility that our Type-Logical analysis can be extended to a more sophisticated theory of discourse structure, as discussed in the literature (Asher \& Lascarides 2003). However, we leave such theoretical problems for future work.

\section{References}

Abels, K. (2003). Successive cyclicity, anti-locality and adposition stranding. Ph.D. dissertation, University of Connecticut.

Acquaviva, P. \& Panagiotidis, P. (20I 2). Lexical Decomposition meets conceptual atomism. Lingue e Linguaggio XI:2, I65-I 80.

Adger, D. (2010). A minimalist theory of feature structure. A. Kibort \& C. Greville (eds) Features: Perspectives on a Key Notion in Linguistics. Oxford: Oxford University Press, I 85-218.

Áfarli, T. (1992). The Syntax of Norwegian Passive Constructions. Philadelphia: John Benjamins.

Alexiadou, A., Law, P., Meinunger, A. \& Wilder, C. (eds) (2000). The Syntax of Relative Clauses. Amsterdam: John Benjamins.

Asher, N. \& Lascarides, A. (2003). Logics of Conversation. Cambridge: Cambridge University Press.

Bernardi, R. \& Szabolcsi, A. (2008). Optionality, scope, and licensing: an application of partially ordered categories. Journal of Logic, Language and Computation 17:3, 237-289.

Bianchi, V. (2002a). Headed relative clauses in generative syntax: Part I. Glot International 6:7, I I 8-I 30 .

- $(2002 \mathrm{~b})$. Headed relative clauses in generative syntax: Part II. Glot International 6:8, $235-247$.

Bolinger, D. (I977). Transitivity and spatiality: The passive of prepositional verbs. A. Makkai, V. B. Makkai, \& L. Heilmann (eds) Linguistics at the Crossroads. Lake Bluff, IL: Jupiter Press, 57-78.

- (I978). Passive and transitivity again. Forum Linguisticum 3, 25-28.

Diessel, H. (2OI 2). Deixis and demonstratives. C. Maienborn, K. von Heusinger 
\& P. Portner (eds) An International Handbook of Natural Language Meaning (Vol. 3). Berlin: Mouton de Gruyter, 2407-243 I.

Embick, D. \& Noyer, R. (200I). Movement operations after syntax. Linguistic Inquiry 32:4, 555-595.

Elbourne, P. (2005). Situations and Individuals. Cambridge, MA: The MIT Press.

Emonds, J. (I985). A Unified Theory of Syntactic Categories. Dordrecht: Foris Publications.

Gehrke, B. \& Grillo, N. (2009). How to become passive. K. Grohmann (ed.) Exploration of Phase Theory: Features, Arguments, and Interpretation at the Interfaces. Berlin: De Gruyter, 213-268.

Hale, K. \& Keyser, S. J. (2002). Prolegomenona to a Theory of Argument Structure. Cambridge, MA: MIT Press.

Harbour, D. (2007). Morphosemantic Number: From Kiowa Noun Classes to UG Number Features. Dordrecht: Springer.

Harley, H. (201 2). Semantics in distributed morphology. K. von Heusinger, C. Maierborn \& P. Portner (eds) Semantics: An International Handbook of Natural Language Meaning. Amsterdam: De Gruyter, 688-709.

Heusinger, K. von (2007). Accessibility and definite noun phrases. M. SchwarzFriesel, M. Consten \& M. Knees (eds) Anaphors in Text: Cognitive, Formal and Applied Approaches to Anaphoric Reference. Amsterdam: Benjamins, I 23-I 44 .

- (20I I). Specificity. K. von Heusinger, C. Maienborn \& P. Portner (eds) Semantics: An International Handbook of Natural Language Meaning, Volume 2 Berlin: de Gruyter, I024-1057.

Holmes, P. \& Hinchliffe, I. (2008). Swedish: An Essential Grammar. Routledge: New York.

Hornstein, N., \& Weinberg, A. (I98I). Case theory and preposition stranding. Linguistic Inquiry I 2:I, 55-9I.

Huddleston, R. \& Pullum, G.K. (2002). The Cambridge Grammar of the English Language. Cambridge: Cambridge University Press.

Ishizuka, T. (2010). Towards a Unified Analysis of Passive in Japanese: A Cartographic Minimalist Approach. Ph.D. Dissertation, UCLA.

Jäger, G. (200I). Anaphora and quantification in Categorial Grammar. M.J. Moortgat (ed.) Logical Aspects of Computational Linguistics, Springer Lecture notes in Artiificial Intelligence 20I4. Springer:Dordrecht, 70-90.

- (2005). Anaphora and Type Logical Grammar. Springer: Dordrecht. 
Jarema, G. \& Libben, G. (eds) (2007). The Mental Lexicon: Core Perspectives. Amsterdam: Elsevier.

Johnson, M \& Bayer, S. (I995). Features and agreement in Lambek Categorial Grammar. Formal Grammar. Proceedings of the Conference of the European Summer School in Logic, Language and Information, Barcelona, I 22-1 27.

Kamp, H., van Genabith, J. \& Reyle, U. (20I I). Discourse representation theory. Handbook of Philosophical Logic I 5. Dordrecht: Kluwer, I 25-394.

Kehler, A. (20I I). Cohesion and coherence. C. Maienborn, K. von Heusinger \& P. Portner (eds) Semantics: An International Handbook of Natural Language Meaning (vol. 2). Berlin: Morton de Gruyter, I963-I987.

Klingvall, E. (20I2). Topics in pseudo-passives. C. Platzack (ed.) Working papers in Scandinavian Syntax 90, 53-80.

Koopman, H. (2000). Prepositions, postpositions, circumpositions, and particles. Koopman, H. (ed.) The Syntax of Specifiers and Heads. London: Routledge, 204-260.

Krifka, M. (200I). For a structured meaning account of questions and answers. C. Fery, \& W. Sternefeld (eds) Audiatur Vox Sapientia. A Festschrift for Arnim von Stechow. Berlin: Akademie Verlag, 287-3 I9.

(2004). The semantics of questions and the focusation of answers. C. Lee, M. Gordon \& D. Büring (eds) Topic and Focus: A Cross-Linguistic Perspective. Dordrecht: Kluwer Academic Publishers, I39-I 5 I.

Law, P. (2005). Preposition stranding. M. Everaert \& H. van Riemsdijk (ed.) The Blackwell Companion to Syntax, Volume III. Malden, MA: Blackwell, $63 \mathrm{I}-684$.

Levelt, W.J.M. (1989). Speaking: From Intention to Articulation. Cambridge (Mass.): The MIT Press.

Maling, J. \& Zaenen, A. (I985). Preposition-stranding and passive. Nordic Journal of Linguistics 8:2, 197-209.

Merchant, J. (200I). The Syntax of Silence. Oxford: Oxford University Press.

- (2004). Fragments and ellipsis. Linguistics and Philosophy, 27:6, $66 \mathrm{I}-738$.

Moortgat, M.J. (20I0). Typelogical grammar. E.N. Zalta (ed.) The Stanford Encyclopedia of Philosophy (Winter 2010 Edition). Stanford.

-. (20I I). Categorial type logics. J. van Benthem \& A. ter Meulen (eds) Handbook of Logic and Language. (2nd ed.). Amsterdam: Elsevier, 95-I 79.

Morrill, G. (20II). Categorial Grammar: Logical Syntax, Semantics, and Processing. Oxford: Oxford University Press. 
Phillips, C. (2006). The real-time status of island phenomena. Language 82:5, $795-823$.

Reuland, E. (20II). Anaphora and Language Design. Cambridge, MA: The MIT press.

Riemsdijk, H. van (I990). Functional prepositions. H. Pinkster \& I. Genee (ed.) Unity in Diversity. Dordrecht: Foris, 229-24 I.

Riemsdijk, H. van. (I998). Head movement and adjacency. Natural Language and Linguistic Theory I 6:5, 633-378.

Stabler, E. (2013). Two models of minimalist, incremental syntactic analysis. Topics in Cognitive Science 5:3, 6I I-633.

Svenonius, P. (2006). The emergence of axial parts. Nordlyd, Tromsǿ University Working Papers in Language and Linguistics, 33:I, 49-77.

- (2010). Spatial P in English. G. Cinque \& L. Rizzi (eds) The Cartography of syntactic Structures: (vol. 6) Oxford: Oxford University Press, I27-I60.

Takami, K. (1992). Preposition Stranding. From Syntactic to Functional Analyses. Berlin and New York: Mouton de Gruyter.

Tseng, J. (2000). The Representation and Selection of Prepositions. Edinburgh: Ph.D. Dissertation.

. (2004). Directionality and the complementation of Dutch prepositions. H. Cuyckens, W. De Mulder \& T. Mortelmans (eds) Adpositions of movement. Belgian Journal of Linguistics I 8, I67-I94.

Tseng, J. (2005). Prepositions and complement selection. A. Villavicencio \& V. Kordoni )(eds) Proceedings of the 2nd ACL-SIGSEM Workshop on the linguistic dimensions of prepositions and their use in computational linguistics formalisms and applications. Colchester: Essex University, I I-I9.

Truswell, R. (2009). Preposition-stranding, passivisation, and extraction from adjuncts in Germanic. J. van Craenenbroeck \& J. Rooryck (ed.) Linguistic variation yearbook 8. Amsterdam: John Benjamins, I3 I-I77.

Ursini, F.-A. (20I I). On the syntax and semantics of "Ser" and "Estar". Lingue \& Linguaggio 9:1, 57-87.

- (20I3a). On the syntax and semantics of "Tener" and "Haber". Lingue \& Linguaggio I I:I, 89-I 20.

- (2013b). Esse and Sta: Auxiliary selection in the Aquilan dialect. Dialectologia I0:I, I07-I34.

- (2013b). Another look at spatial prepositions and the modification problem. Iberia: An International Journal of Theoretical Linguistics 5:2, 38-84. 
. (20I3C). On the syntax and semantics of spatial Ps in Spanish. Borealis: An International Journal about Hispanic Linguistics 2:I, I I7-I 66.

(20I5a). The morphology of spatial P: Is a unitary perspective possible? G. Boyes et al. (eds) Proceedings of Les Decembrettes 8. Toulouse: Mirail, I-20.

- (20 I 5 b). On the syntax and semantics of Italian spatial prepositions. Acta Linguistica Hungarica 63:I, 3-57.

Ursini, F.-A. \& Akagi, N. (20I3a). On the distributed morphology and semantics of spatial Ps. I.-J. Lee \& U. Dolgormaa (eds) Proceedings of the $15^{t h}$ Seoul International Conference on Generative Grammar (SICOGG I5). Seoul: Hankuk University Press, 447-468.

Vermaat, W. (2005). The Logic of Variation: A Cross-linguistic Account of Wh-question Formation. Doctoral Dissertation, Utrecht.

Ward, G. \& Birner, M. (2012). Discourse effects of word order variation. C. Maienborn, K. von Heusinger \& P. Portner (eds) Semantics: An International Handbook of Natural Language Meaning (vol. 2). Berlin: Mouton de Gruyter, I934-1963.

Zeevat, H. (20II). Discourse relations. C. Maienborn, K. von Heusinger \& P. Portner (eds) Semantics: An International Handbook of Natural Language Meaning, Volume I. Berlin: Mouton de Gruyter, 946-972 